\title{
CFD and CAA Analysis of Centrifugal Fan for Noise Reduction
}

\author{
S. Ramakrishna \\ GVP College of \\ Engineering (A) \\ Visakhapatnam
}

\author{
Vommi Krishna \\ ANITS \\ Visakhapatnam
}

\author{
A. Ramakrishna \\ A. U College of \\ Engineering $(A)$ \\ Visakhapatnam
}

\author{
K. Ramji \\ A. $U$ College of \\ Engineering (A) \\ Visakhapatnam
}

\begin{abstract}
Centrifugal fans usually operate at high rotating speeds and hence generate high levels of noise whose reduction over a broad range of operating conditions is a key concern for the designer. An important first step in this direction is identification of noise sources and its quantification. For this purpose, Computational Fluid Dynamics (CFD) and computational aeroacoustic analyses is performed on centrifugal fans with backward impeller, radial impeller and forward impellers using CFD code FLUENT. To validate these results noise measurements are performed on centrifugal fans with backward impeller, radial impeller and forward impellers. The results so obtained from numerical analyses are compared with the measurement results. It is found that there is good agreement between numerical and experimental results. From these results it is observed that least noise of $92.6 \mathrm{~dB}(\mathrm{~A})$ and high flow rate of $0.399 \mathrm{~m}^{3} / \mathrm{sec}$ occurs with backward impeller whereas large noise of $102.5 \mathrm{~dB}(\mathrm{~A})$ and least discharge of $0.365 \mathrm{~m}^{3} / \mathrm{sec}$ is observed with forward impeller. The present study concludes that backward impeller radiates less noise and high discharge compared to radial and forward impellers.
\end{abstract}

\section{Keywords}

Centrifugal fan, backward impeller, radial impeller, forward impeller, CFD, aeroacoustics

\section{INTRODUCTION}

A Centrifugal fan is a roto-dynamic fan that uses a rotating impeller to deliver high flow rate with moderate pressure rise. Due to numerous applications in industries, researches on centrifugal fans and their noise related problems is increasing in recent times. Christopher [1] conducted experiments on three different types of fans to determine the major noise generation mechanisms. Wu [2] demonstrated that monopole exists for a fan running inside heating ventilation and air-conditioning unit of a vehicle. Sonetal [3] simulated the effects of bell mouth geometries on the flow rate of centrifugal fan numerically using a FLUENT. Chen-kang and Mu-En [4] used the CFD package FLUENT to simulate four backward impeller curved air foil centrifugal fans. Cao and $\mathrm{Hu}$ [5] proposed a cluster design approach to achieve a good aerodynamic and acoustic performance of a ventilation system. Moreland [6] explained the housing effect on centrifugal fan for noise reduction. Lu et al. [7] presented a numerical optimization to reduce the vibration and noise of a centrifugal fan volute. The work of Scheit et al. [8] is concerned with analyzing the flow structures inside isolated radial impellers together with the far-field sound radiated from them in order to optimize the aerodynamic and acoustic performance. Prezelj and Cudina [9] concluded that the dominant noise source of a centrifugal fan can be attributed to the aerodynamically generated noise which exceeds the vibration-induced noise for more than $10 \mathrm{~dB}$ in a broad frequency range. Mao et al. [10] presented aerodynamic tonal noise radiated from a centrifugal fan using a hybrid computational aeroacoustics approach that couples numerical flow with an implementation of the acoustic analogy. Mao et al. [11] calculated the noise radiating from rotating blades surrounded by a centrifugal volute by combining a hybrid computational aeroacoustic method with the thin-body boundary element. The present problem considers a single stage centrifugal fan consisting 12 blades driven by an electric motor. Experimental as well as numerical study on the centrifugal fan with three types of impellers has been carried out to evaluate their aeroacoustic and aerodynamic performance at optimum efficiency and corresponding operating speed of $2260 \mathrm{rpm}$.

\section{EXPERIMENTAL STUDIES}

\subsection{Experimental setup}

The Experimental set up consists of centrifugal fan driven by $\mathrm{a} / \mathrm{c}$ motor through a step pulley arrangement to obtain different speeds through a step pulley arrangement to obtain three different speeds. The capacity of motor is 3.375 $\mathrm{KW}$ and all experiments are carried out at optimum speed $2260 \mathrm{rpm}$. The efficiency of motor is $80 \%$ and V-belt transmission efficiency $95 \%$ is consider for calculation of input power to a centrifugal fan. The motor is mounted on an adjustable bed and the fan output (discharge) is controlled by a sluice valve. All the measurements are carried out at optimum operating conditions to compare the noise and flow of centrifugal fan with backward, radial and forward impellers.

Figure 1 shows the experimental setup for aeroacoustic measurements. The noise of centrifugal fan was measured by Bluer \& Kjaer sound level meter-2260, which is a precision hand-held sound level meter with real-time displays of 1/3octave band in the range of $6.3 \mathrm{~Hz}-20 \mathrm{kHz}$. Sound analysis software BZ7210 was used to analyze data obtained from sound level meter. The noise measured in room size of $5 \mathrm{~m} \times 5 \mathrm{~m} \times 3 \mathrm{~m}$. The background room noise is $47.2 \mathrm{~dB}(\mathrm{~A})$ is considered for all noise measurements. The noise and flow rate of all backward, radial, forward impellers of centrifugal fan are compared at optimum rotational speed $2260 \mathrm{rpm}$. The sound pressure level difference between the centrifugal fan and background noise is beyond $10 \mathrm{~dB}$, so the correction factor drops below $0.5 \mathrm{~dB}$ and therefore background noise becomes insignificant in present noise calculations. Figure 2 shows the experimental setup for aerodynamic measurements. An orifice meter is fixed in the outlet of pipe line to measure the actual discharge. A pitot tube and thermometer set is provided at the outlet to measure the velocity and temperature. U-tube manometers are provided to measure the pressure difference across the orifice meter and pitot tube. 


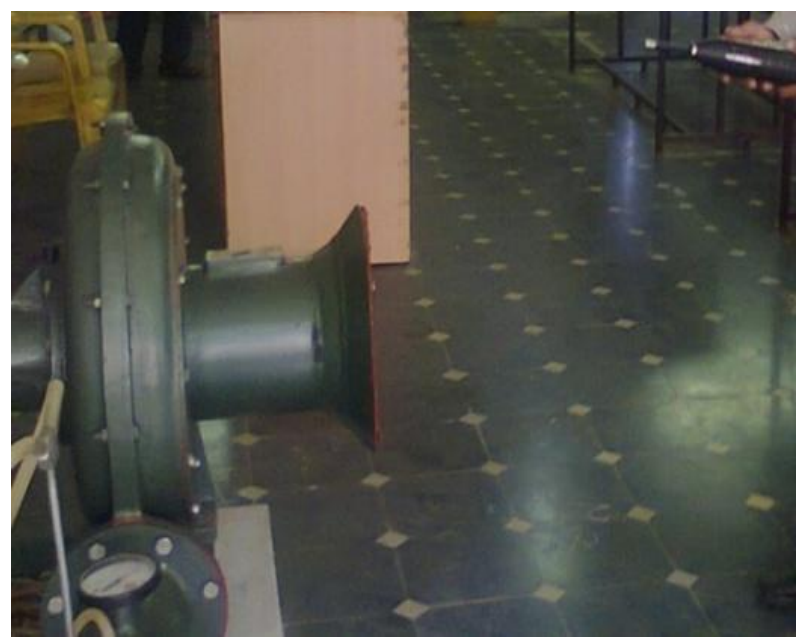

Figure1. Experimental set up for aeroacoustic measurements

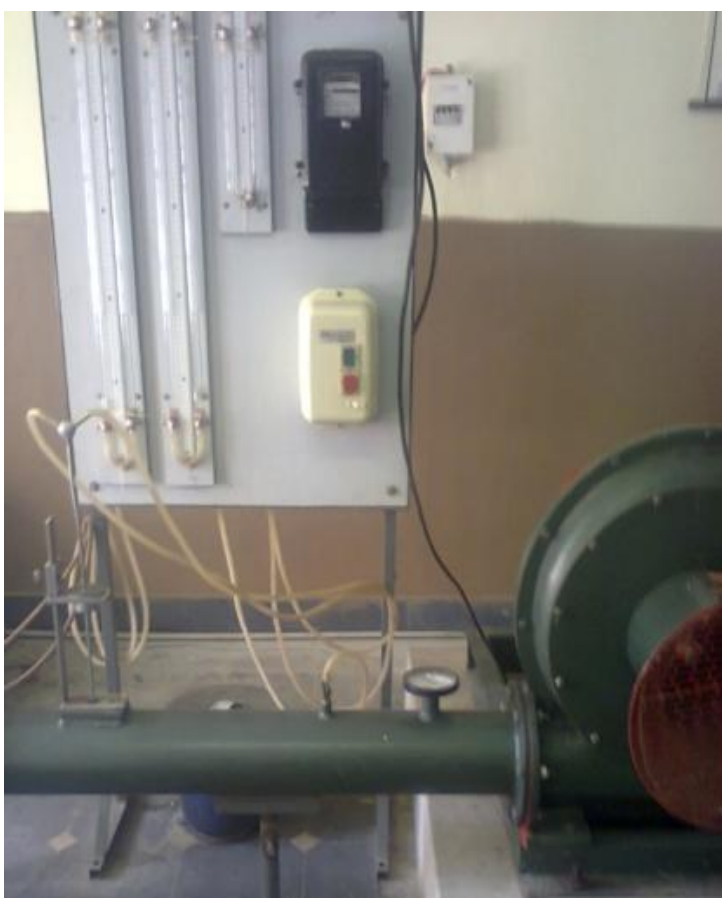

Figure 2. Experimental set up for aerodynamic measurements.

\subsection{Results and discussion}

The noise levels of centrifugal fan with three different types of impellers namely backward impeller, radial impeller and forward impeller are measured and the results are compared at optimum operating conditions. Results are presented for the measurement point located at $1 \mathrm{~m}$ upstream of the fan inlet, with the microphone aligned to the impeller shaft for all noise measurements. 1/3 octave band noise analyses are carried out for all impellers at optimum operating conditions. The sound pressure levels of all fans is measured at constant speed of 2260rpm.

The A-weighted sound pressure levels has been used since it reflects the noise perceived by the human ear more closely. Broadband analysis is used to obtain noise spectra in the range of $0-16.0 \mathrm{kHz}$. Figure 3 shows the $1 / 3$ octave band sound pressure spectrum of backward impeller at inlet. These results show that tonal noise is predominant in low frequency range $0-1000 \mathrm{~Hz}$ only, while broadband noise extends through the entire range of frequency $0-16.0 \mathrm{kHz}$. The overall sound pressure level for backward impeller is $92.6 \mathrm{~dB}(\mathrm{~A})$. Figure 3 denotes peak value of $82.3 \mathrm{~dB}$ which is observed at fundamental blade passing frequency $(452 \mathrm{~Hz})$. Besides, another peak value of $78.8 \mathrm{~dB}$ is observed at first harmonic of blade passing frequency $(904 \mathrm{~Hz})$. Some of the noise peaks of blade passing frequency and their higher harmonics, could be due to resonant frequency of the noise generated by electric motor, vibration due to unbalanced rotating masses. Figure 4 shows the $1 / 3$ octave band sound pressure spectrum of radial impeller at inlet. The overall sound pressure level for radial impeller is $97.3 \mathrm{~dB}(\mathrm{~A})$ which is $4.7 \mathrm{~dB}(\mathrm{~A})$ more compared to backward impeller. Figure 5 shows the $1 / 3$ octave band sound pressure spectrum of forward impeller at inlet. It generates more noise when compared to backward impeller and radial impeller. The overall sound pressure level for forward impellers is $102.5 \mathrm{~dB}(\mathrm{~A})$. It is $9.9 \mathrm{~dB}$ more than the noise generated by backward impeller and $5.2 \mathrm{~dB}$ more than that of radial impeller. Lesser noise generated by backward impeller when compared to radial impeller and forward impeller may be due to smooth flow at the inlet and outlet. Figure 6 shows the comparison of $1 / 3$ octave band sound pressure spectrum of the three types of impellers. It shows that all fans generate peak noise between $450 \mathrm{~Hz}$ to $1000 \mathrm{~Hz}$.

At the optimum operating condition the high discharge is observed for backward impeller is $0.399 \mathrm{~m}^{3} / \mathrm{sec}$ and least discharge $0.365 \mathrm{~m}^{3} / \mathrm{sec}$ is observed for forward impeller. Radial impeller discharge is $0.378 \mathrm{~m}^{3} / \mathrm{sec}$ is in-between the discharge of backward impeller and radial impellers. Maximum pressure of $2079.5 \mathrm{~N} / \mathrm{m}^{2}$ and high velocity of 29.6 $\mathrm{m} / \mathrm{sec}$ is observed for backward impeller. Low pressure of $1471.8 \mathrm{~N} / \mathrm{m}^{2}$ and least velocity of $25.66 \mathrm{~m} / \mathrm{sec}$ is observed for forward impeller. From these results high discharge, velocity and pressure is observed with backward impeller and least velocity, discharge and pressure is observed with forward impeller whereas aerodynamic and aeroacoustic results of radial impeller is in between these impellers. 


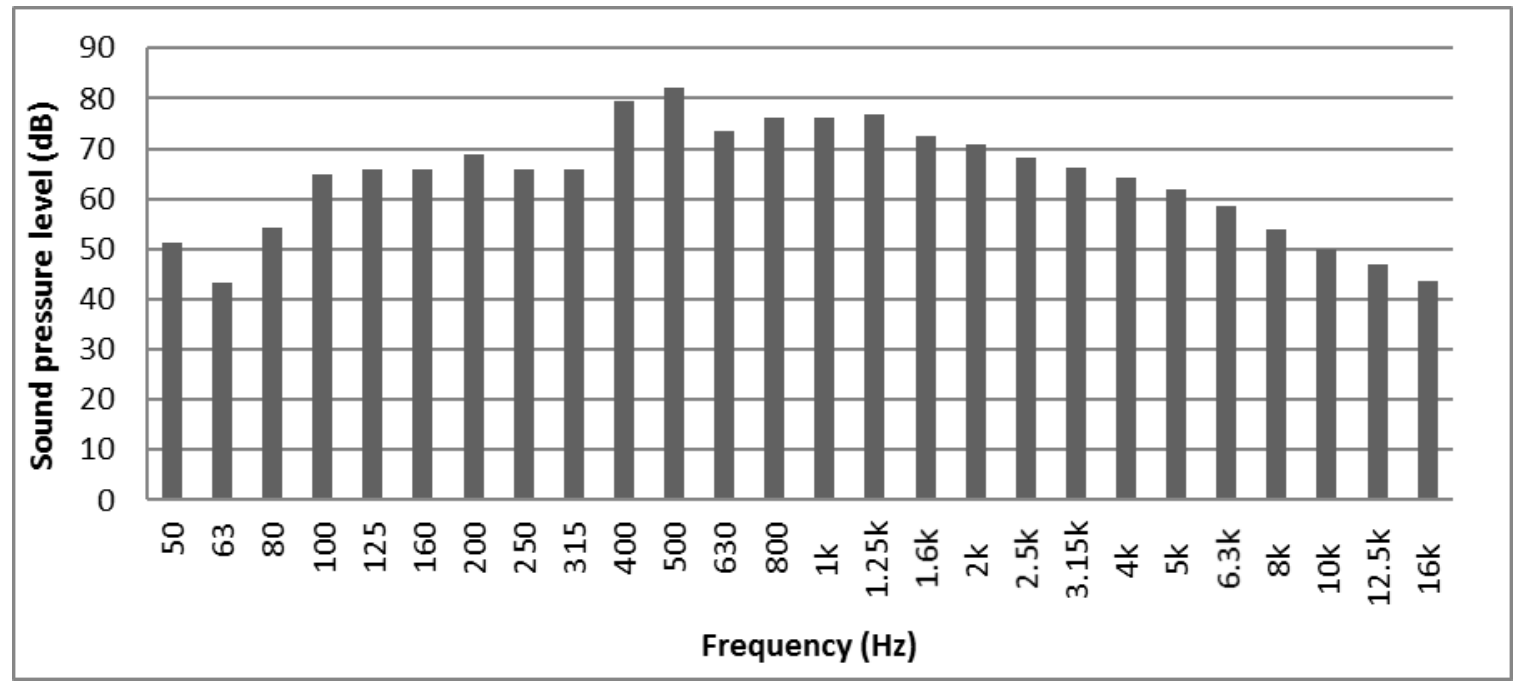

Figure 4. 1/3 octave band sound pressure spectrum of backward impeller at inlet

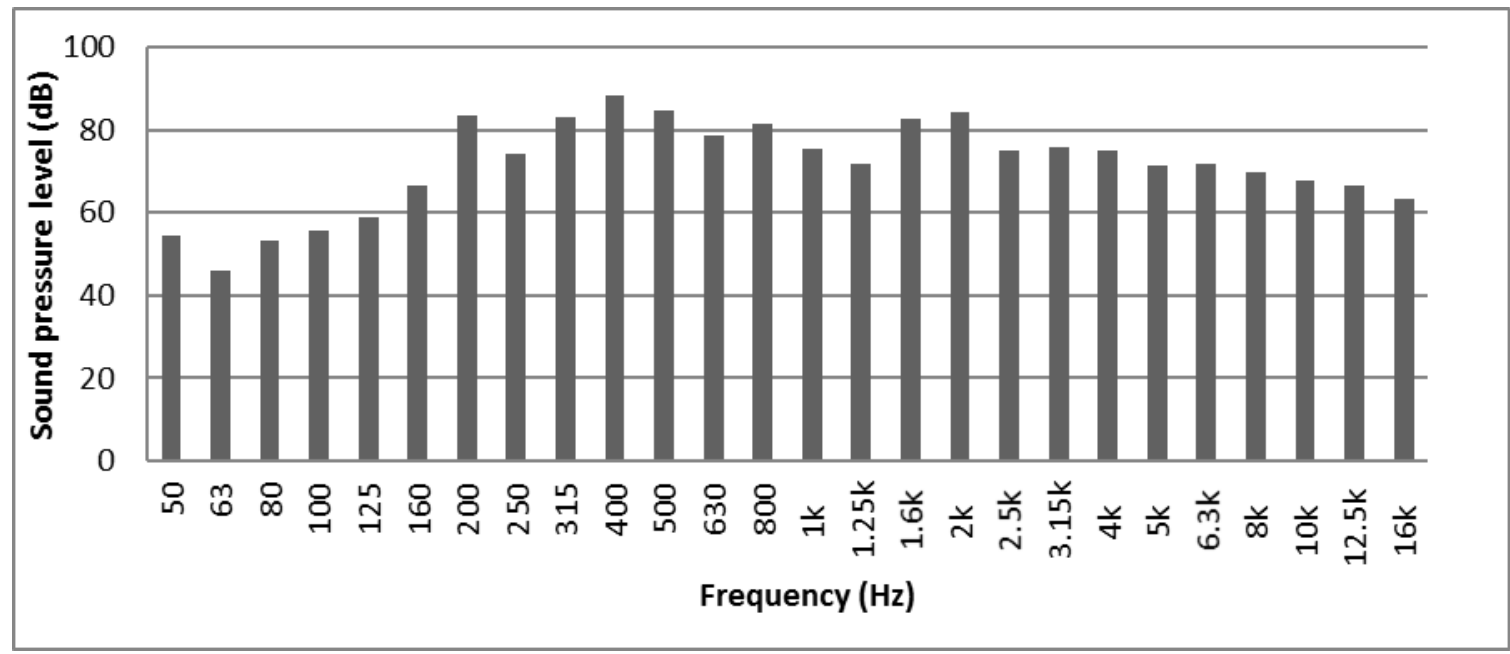

Figure 4. 1/3 octave band sound pressure spectrum of radial impeller at inlet

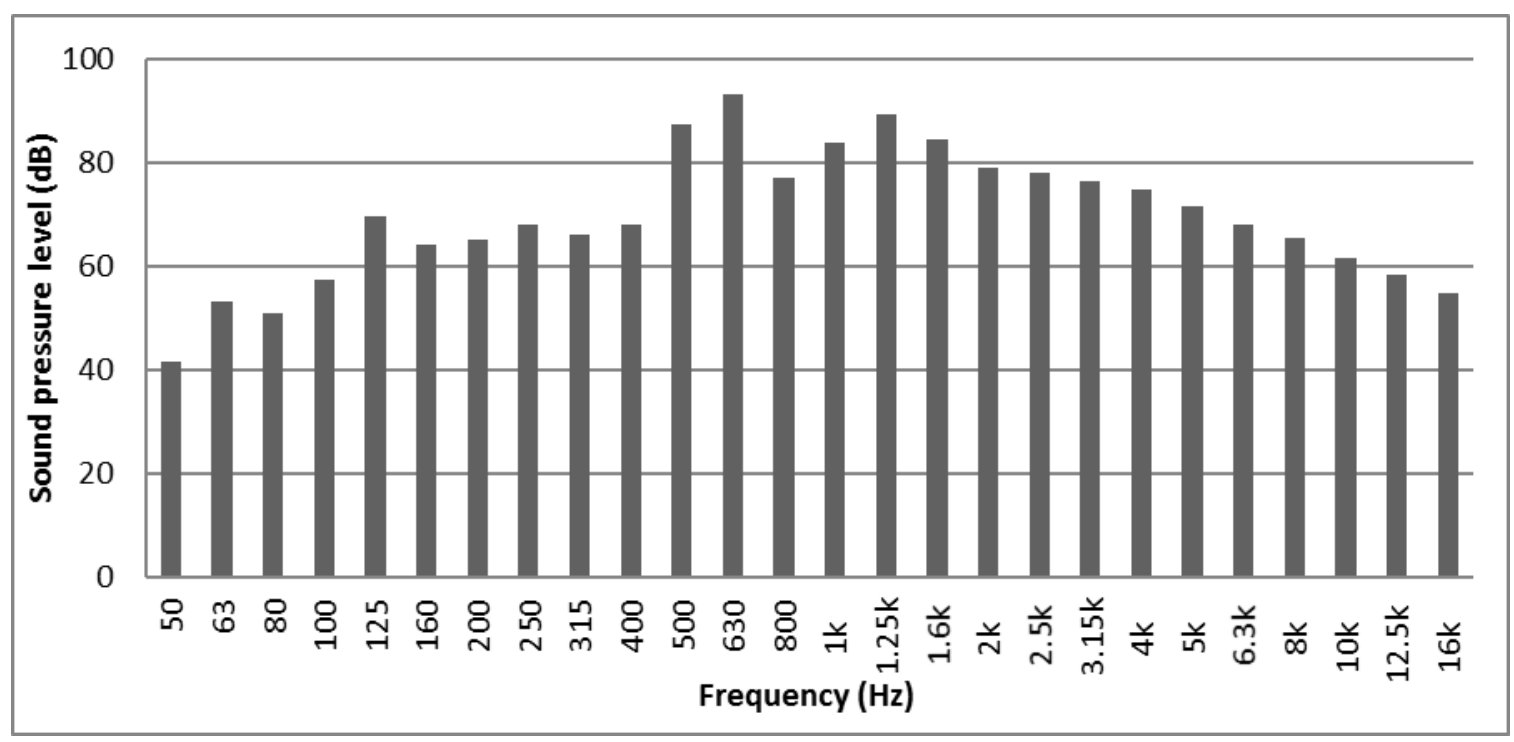

Figure 5. 1/3 octave band sound pressure spectrum of forward impeller at inlet 


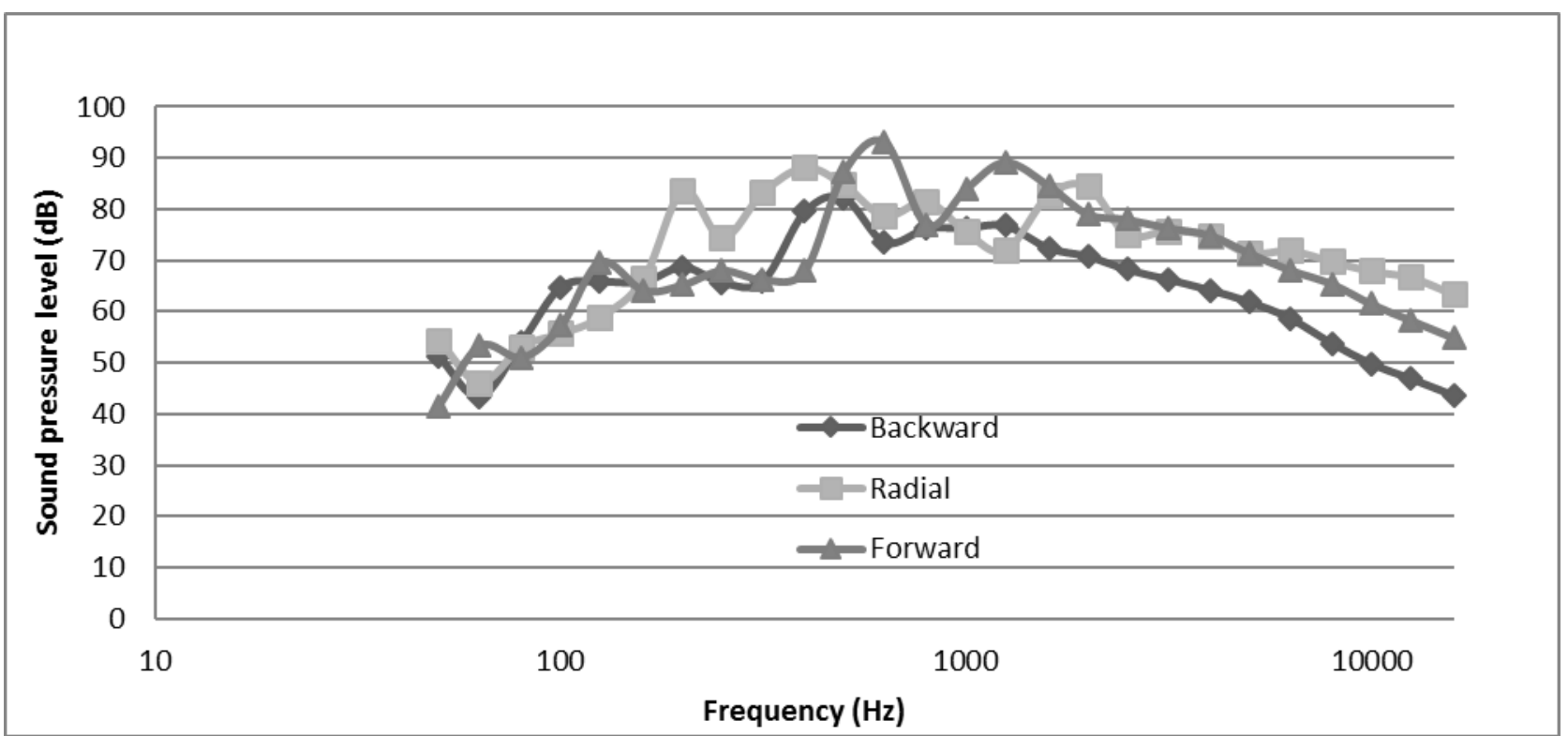

Figure 6. Comparison of $1 / 3$ octave band sound pressure spectrum of three types of impellers

\section{NUMERICAL STUDIES}

\subsection{Geometric Modelling}

In the present problem reverse engineering methodology is used to obtain dimensions and three-dimensional model of centrifugal fan. Reverse engineering method is simply an effort to try and recreate the design of a product by examining the product itself. The impeller is major noise source compared to the casing. So in the present numerical simulations are carried out by taking the impeller is a noise source. Solid model of backward impeller, radial impeller and forward impellers is obtained using CATIA v5r10.

The outlet diameter of all impellers is $440 \mathrm{~mm}$, inlet diameter is $200 \mathrm{~mm}$ and it contains 12 equally spaced blades. The minimum distance between the impeller and the casing is $55 \mathrm{~mm}$. The widths of the impeller and casing are $100 \mathrm{~mm}$ and $210 \mathrm{~mm}$ respectively. Figure 7 show the solid model of backward impeller and Figure 8 show the solid model of computational domain used for present noise and flow simulations.

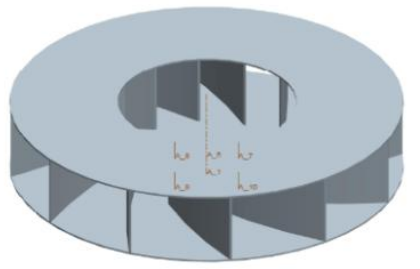

Figure 7. Solid model of backward impeller

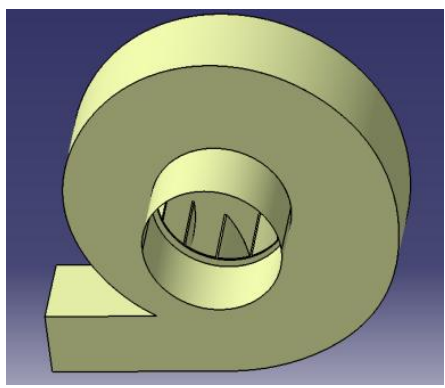

Figure 8. Solid model of computational domain

\subsection{CFD and CAA Analyses}

The objectives of the present Computational fluid dynamics and Computational aeroacoustics analyses are to find the noise sources and sound pressure level of centrifugal fan at optimum efficiency operating point. Commercially available grid generation code GAMBIT is used to mesh the domain of centrifugal fan. Three dimensional structural tetrahedral grids are generated to descretize the domain. In order to obtain better results tetrahedral element has been used by taking advantage of mesh consistency.

The domain is discretized by minimum 10 linear elements per source wavelength to increase the accuracy of the acoustic propagation. Different grids of element sizes 12, 10, 8 and 6 are generated for the entire computational domain of centrifugal fan with backward impeller. The simulations are carried out for all grids in Fluent for comparison of results. From the results it is observed that close results are observed with element size 8 and 6 . So grid with element size 8 is used for noise and flow simulations of centrifugal fan with backward impeller, radial impeller and forward impellers. After mesh convergence with element size 8 , there are 1.45 million tetrahedral elements are generated for the entire domain of centrifugal fan with backward impeller. Figure 9 show the mesh generated near the centrifugal fan with backward impeller and casing. It is clearly shows that denser mesh is near blade surface to capture the flow properties with significant quality. The similar meshes are also generated for centrifugal fan with forward and radial impellers.

The numerical simulations have been carried out with a finite volume code FLUENT. Three dimensional segregated implicit solver is used in the present analysis. Second-order implicit method is used for time discretization. The turbulent nature of the flow is incorporated through the Large Eddy simulation which is chosen as viscous model since it needs time dependent solution for aeroacoustic solution and is not highly dependent on geometrical conditions. Fluid zone in the volume is defined as "moving mesh" and rotate at speed of $2660 \mathrm{rpm}$ in X-direction. Merged equations were solved iteratively at time increment, and set in such way that 10,000 increments correspond to one single revolution of the fan. The corresponding time step of $1.23148 \times 10^{-5} \mathrm{~s}$ for angular speed of $2660 \mathrm{rpm}$ is used for the present simulations. The wall 
forming the centrifugal fan blade is assigned a relative rotational velocity of zero with respect to adjacent cell zone. A pressure inlet is prescribed at inlet and outlet, pressure condition is set at outlet of centrifugal fan. Computation is terminated when changes in solution variables from one iteration to the next is negligible. Fig. 10 shows the boundary conditions imposed on the computational domain of centrifugal fan.

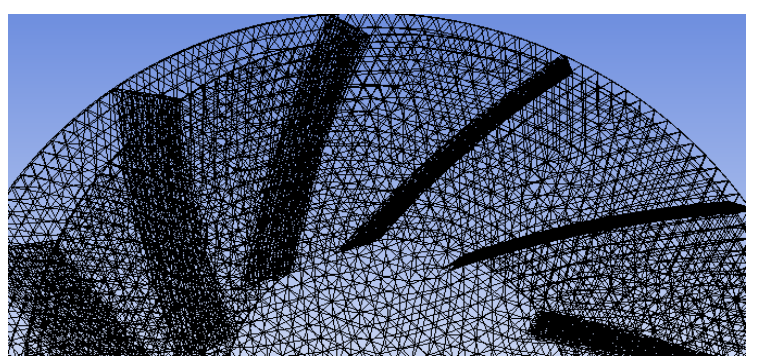

Figure 9. Mesh near the blade and casing

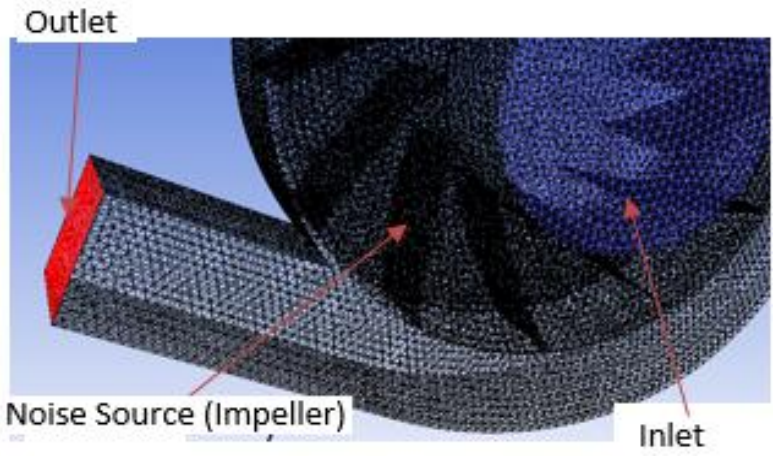

Figure 10. Boundary conditions on computational domain of centrifugal fan

\subsection{Results and Discussion}

Table 1 shows the comparison of simulation and measurement results of noise and flow rate of the three types of impellers. The noise source used for present simulations is only impeller and flow field in the impeller and volute is defined by the domain boundary conditions. For all impellers noise and flow parameters are simulated at same as experimental optimum operating conditions to compare the numerical and experimental results.

The receiver point is aligned to the impeller shaft and is located at $1 \mathrm{~m}$ upstream of the centrifugal fan inlet. This is a common location for microphones in the test setup. Figure 11 shows noise prediction graph of backward impeller at inlet. To observe broadband noise, frequencies from $0 \mathrm{~Hz}$ to 4,000 $\mathrm{Hz}$ are plotted. As shown in Figure 11 broadband noise extends over the entire range of frequency and the overall sound pressure level value obtained from numerical simulation is $85.8 \mathrm{~dB}(\mathrm{~A})$ at inlet for backward impeller, 88.2 $\mathrm{dB}(\mathrm{A})$ for radial impeller and $93.9 \mathrm{~dB}(\mathrm{~A})$ for forward impeller. From these results it is observed that the blade of the fan is the main contributor to the aeroacoustic characteristics of the flow field. From the unsteady flow results it is found that the predicted flow rate for all fans is same as actual flow obtained from measurements. Non-uniform flow at inlt causes non-uniform aerodynamic forces on the blades as their angular positions change. This generates noise at blade passing frequency and its harmonics and is one of the major noise sources of centrifugal fan. The basic noise source in centrifugal fan is dipolar noise source as noise is generated due to aerodynamic pressure fluctuation. The sound pressure levels at inlet of the radial impeller and forward impellers centrifugal fan is shown in Figure 12 and Figure13 respectively. From these results it is observed that error between predicted and measured aeroacoustics and aerodynamic results of all centrifugal fans is within $15 \%$.

Table 1 Aeroacoustics and Aerodynamic results comparison

\begin{tabular}{|l|l|l|l|l|l|l|l|l|l|}
\hline & & \multicolumn{3}{|l|}{ Backward impeller } & \multicolumn{2}{l|}{ Radial impeller } & \multicolumn{2}{l|}{ Forward impeller } \\
\cline { 2 - 11 } & $\begin{array}{l}\text { Measure } \\
\text { ment }\end{array}$ & $\begin{array}{l}\text { Predicti } \\
\text { on }\end{array}$ & $\begin{array}{l}\text { Error } \\
(\%)\end{array}$ & $\begin{array}{l}\text { Measurem } \\
\text { ent }\end{array}$ & Prediction & $\begin{array}{l}\text { Error } \\
(\%)\end{array}$ & $\begin{array}{l}\text { Measure } \\
\text { ment }\end{array}$ & $\begin{array}{l}\text { Predictio } \\
\mathrm{n}\end{array}$ & $\begin{array}{l}\text { Error } \\
(\%)\end{array}$ \\
\hline $\begin{array}{l}\text { Overall } \\
(\mathrm{dB}(\mathrm{A}))\end{array}$ & 92.6 & 85.8 & 7.3 & 97.3 & 88.2 & 9.2 & 102.5 & 93.9 & 8.4 \\
\hline $\begin{array}{l}\text { Pressure at outlet } \\
\left(\mathrm{N} / \mathrm{m}^{2}\right)\end{array}$ & 2079.5 & 2320 & 11.56 & 1481.9 & 1653 & 12.34 & 1471.8 & 1680 & 13.3 \\
\hline $\begin{array}{l}\text { Velocity } \\
(\mathrm{m} / \mathrm{sec})\end{array}$ & 29.6 & 32.56 & 10.00 & 28.95 & 33.29 & 14.99 & 25.66 & 28.73 & 12.0 \\
\hline Discharge $\left(\mathrm{m}^{3} / \mathrm{s}\right)$ & 0.399 & 0.453 & 13.53 & 0.378 & 0.434 & 14.81 & 0.365 & 0.415 & 13.6 \\
\hline Total Efficiency & 60.35 & 67.54 & 11.9 & 39.70 & 43.45 & 9.4 & 36.58 & 41.34 & 13.1 \\
\hline
\end{tabular}




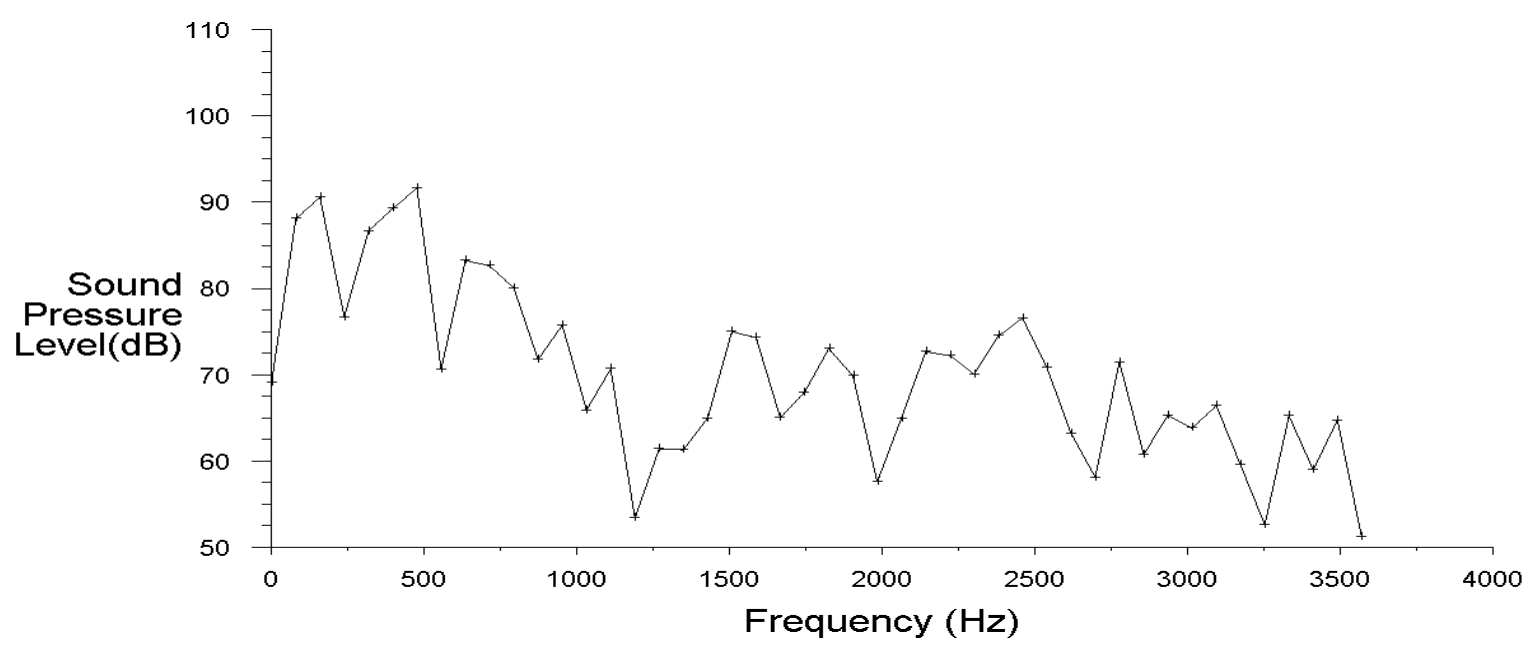

Figure 11 Noise prediction graph of backward impeller at inlet

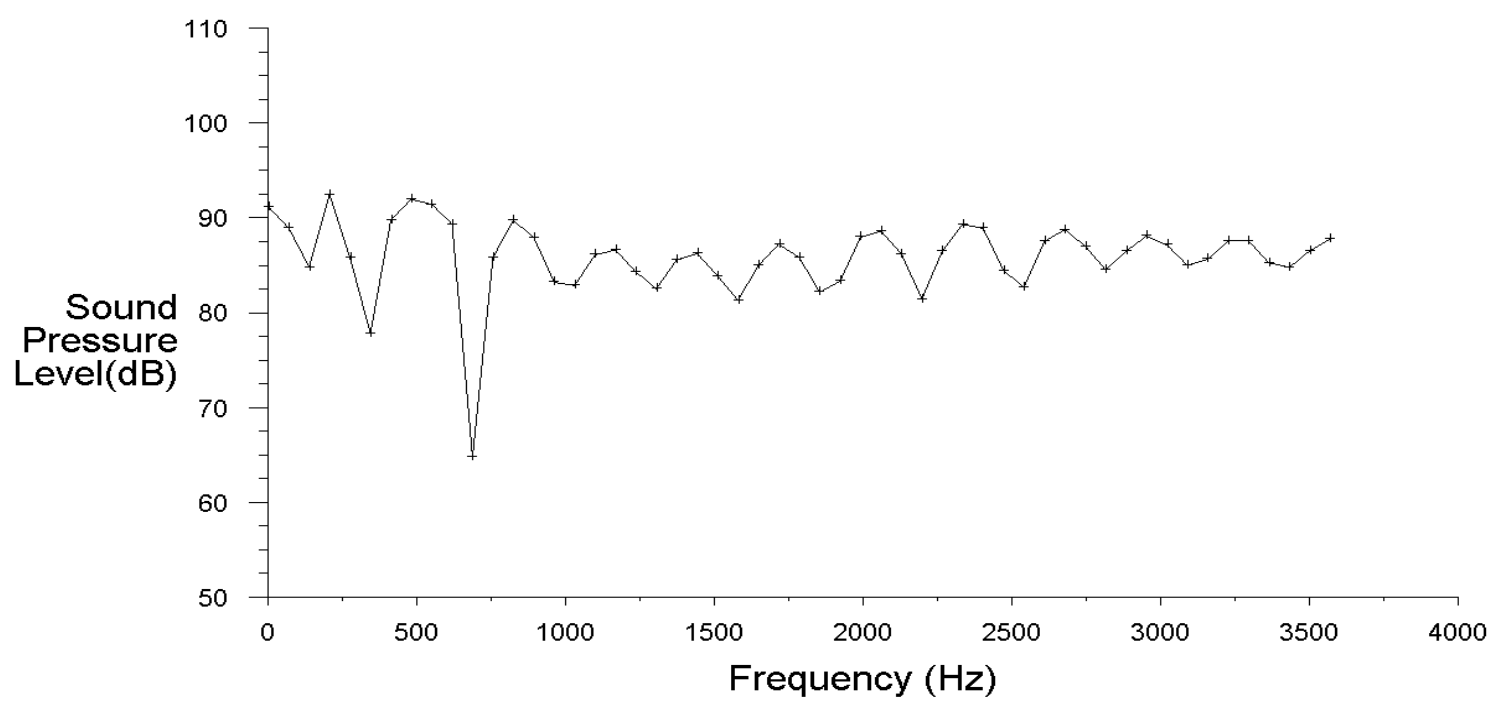

Figure 12. Noise prediction graph of radial impeller at inlet

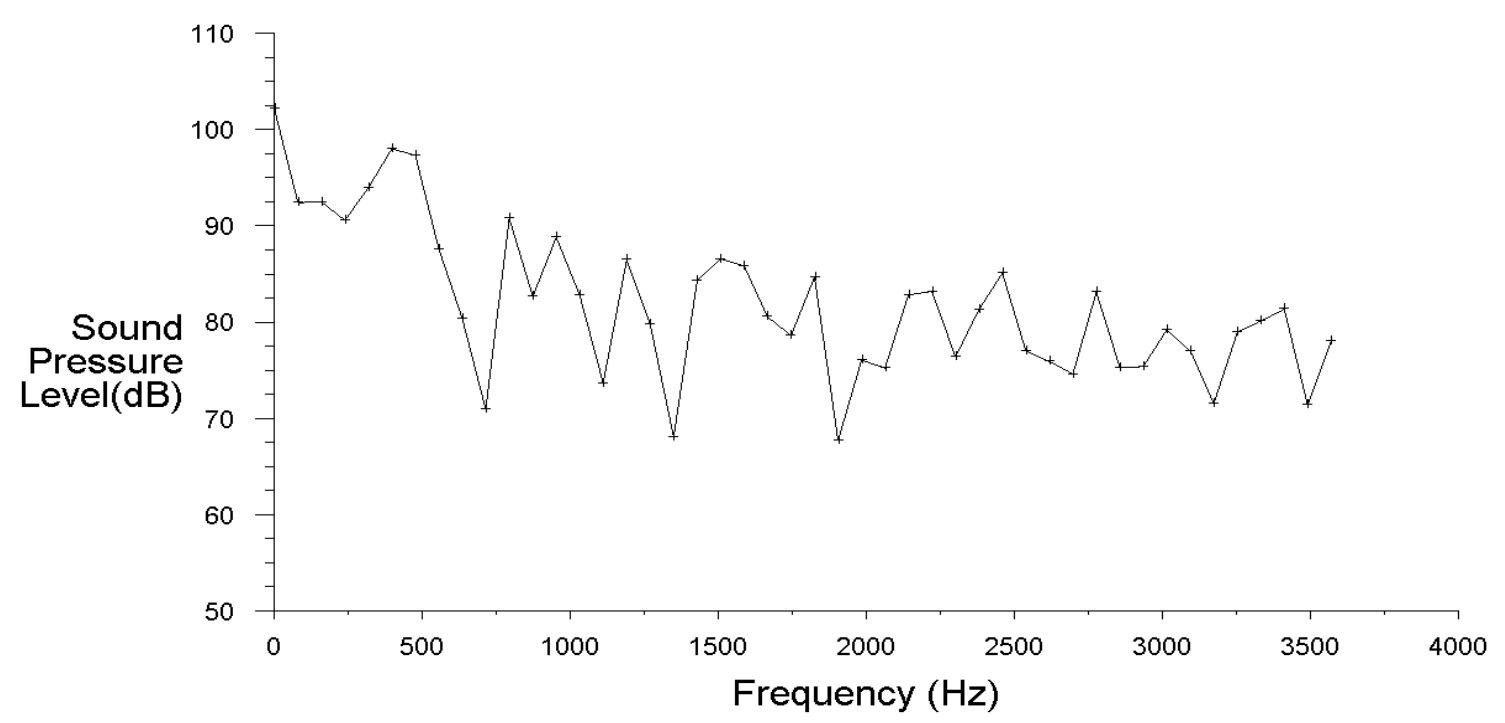

Figure 13. Noise prediction graph of forward impeller at inlet 


\section{CONCLUSIONS}

The aerodynamic and aeroaccoustic parameters of centrifugal fan with backward impeller, radial impeller and forward impellers are predicted and plotted and is results obtained from numerical analyses are compared with the measurement results. Close correlation is observed between experimental and numerical results. From these results it is concluded that centrifugal fan with backward impeller generates less noise and high discharge compared to radial and forward impellers. Least discharge and noise is observed with forward impeller whereas aerodynamic and aeroacoustic results of radial impeller is in between backward and radial impellers.

\section{REFERENCES}

[1] Christopher, L., 1998, Prediction and Reduction of Centrifugal Fan Noises, J. Acoust. Soc. Am., 103(5):3045-3045.

[2] Sean, Wu, 2002, On Sound Generation Mechanism by a Centrifugal Fan, J. Acoust. Soc. Am., 111(5):2424-2424.

[3] Son, Pham Ngoc., Kim, Jaewon.,and Ahn, E. Y., 2011, Effect of Bell Mouth Geometries on the Flow Rate of Centrifugal Fan, J. Mech. Sci. Tech., 25 (9):2267-2276.

[4] Huang, Chen-kang., and Hsieh, Mu-En., 2009, Performance Analysis and Optimized Design of Backward Curved Airfoil Centrifugal Fans, Technical Report, ASHRAE, USA.
[5] Cao, R, and Hu J., 2005, A Cluster Design Approach to Noise Reduction in Centrifugal Fan, Int. J. Vent, 3(4):345-352.

[6] Moreland, J.B., 1974, Housing Effect on Centrifugal Fan Noise, J. Sound Vib., 36(2):191-205.

[7] Lu, F. A., Qi, D.T., Wang, X.J., Zhou, Z., and Zhou, H.H., 2012, A Numerical Optimization on the Vibroacoustics of a Centrifugal Fan Volute, J. Sound Vib., 331(10): 2365-2385.

[8] Scheit,C., Karic,B., and Becker,S., 2012, Effect of Blade Wrap Angle on Efficiency and Noise of Small Radial Impeller Fan Impellers-A Computational and Experimental Study, J. Sound Vib., 331(5):996-1010.

[9] Prezelj, J., and Cudina, M.,2011, Quantification of Aerodynamically Induced Noise and Vibration-Induced Noise in a Suction Unit,Proc. Inst. Mech. Eng. C,225(3):617-624

[10] Mao, Y., Qi, D., Liu, X.,and Tang, H.,2008, Numerical prediction of aerodynamic tonal noise radiated from a centrifugal fan,Proc. Inst. Mech. Eng. A, 222(8):831-842.

[11] Mao, Y., and Qi, D., 2009, Computation of Rotating Blade Noise Scattered by a Centrifugal Volute,Proc. Inst. Mech. Eng. A, 223(8):965-972. 